\title{
Personal Records from My Tattoo Parlour: Deep Emotions Drawn as Life-Long Pictures on the Skin's Canvas
}

\section{Liz Kierstein}

Independent Tattoo Artists, Copenhagen, Denmark

\begin{abstract}
The author, who has been a professional tattooist for years, reports four individuals whose tragic life events led to decisions to be tattooed with illustrations of their life stories. The authors' personal experiences with tattooistclient interactions and clients' expectations and demands are reviewed. During the last decade, tattooing has moved in the direction of becoming more individualized and is often very personal. The working process and the intimacy between the client and tattooist create a comfort zone of trust and loyalty.
\end{abstract}

() 2015 S. Karger AG, Basel

\section{Introduction}

To introduce myself, I have been a Danish professional tattooist for 25 years. I have always been fascinated by the art of tattooing and have aimed to achieve and practice high professional standards. For periods, I also have worked in the USA and Spain. In this chapter, I shall report my personal experiences as a type of testimonial, starting with case reports from my parlour that have been printed in this book with permission.

\section{Case Reports}

\section{Case 1: MP, 21-Year-Old Man}

Tattoo: Memory tattoo on left side of chest (fig. 1a, b).

Design: Text in Danish: 'Et påtvunget ansvar, der ikke var ønsket - Livet. Så hvorfor ikke få det bedste ud af det?' English translation: 'An imposed, not wanted responsibility - Life. So, why not make the best out of it?'

Reason for Tattoo: His little brother committed suicide at the age of 19 years in January 2014 after 2 previous attempts.

Knowing that the youngest child of 3 would most likely succeed in committing suicide, the family tried to help him in any way they could. The boy suffered from depression and schizophrenic attacks after his parents divorced. He was frequently in fights, had a bad temper and found no reason to live. He left behind a family in grief, especially his older brother, MP, who wanted the life and tragedy of his little brother to be remembered. MP opted for text carved into his skin because the loss of his brother will be forever on his mind.

Encouraged by his cousin, who is a client at my studio, MP and his cousin showed up at my parlour one day and told their story. As a professional, I guided the young client with regard to the correct size of the 

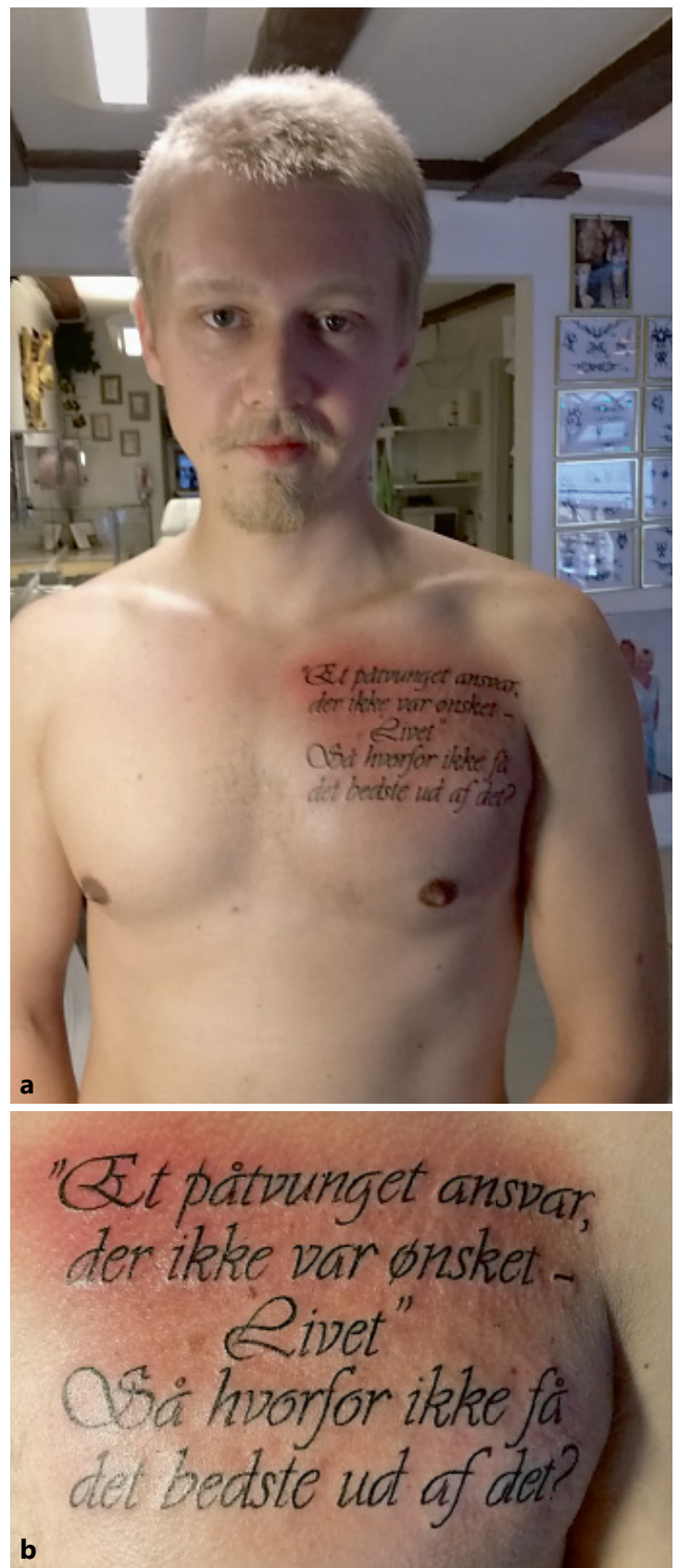

Fig. 1. a, b Memory tattoo. Tattoo and photo by author. lettering in the tattoo and the correct placement of the tattoo on his chest over his heart. After a few days, MP returned and showed his preferred type of lettering, and he had chosen a decent size. We fitted the sentences, and the tattoo was performed. The redness of the surrounding skin in the photos is transient and due to tattoo needle trauma.

\section{Case 2: KP, 48-Year-Old Male}

Tattoo: Black and grey wash on right upper arm (fig. 2).

Design: Woman's face, pocket watch and devil.

Reason for Tattoo: His wife, who was only 63 years of age, recently died from Alzheimer's disease. The face symbolized the beauty of his wife, the pocket watch showed that time was running out, and the devil's face symbolized the terrible nature of the disease.

The client had never received a tattoo before and was trying to find comfort and some sort of acknowledgment of the fact that time really was running out. He wanted to mark his body during this terrible time, while waiting for his wife to pass away at a special care home.

\section{Case 3: BNA, 40-Year-Old Woman}

Tattoo: Colorful and on the left ankle (fig. 3).

Design: Tiger cub.

After a lot of homemade tattoos, this client finally came to me and got her 'first' professional tattoo. BNA's boyfriend and pals doubted that this was a real tattoo! The client was very, very happy and probably found comfort with this little innocent cub, which was helpless and fragile like BNA herself. She had been on drugs for years.

\section{Case 4: JM, 53-Year-Old Male, Teacher and Guitar Builder}

Tattoo: Left forearm - his 'music arm' (fig. 4).

Design: A graphic photo of Jimi Hendrix.

JM was divorced from his wife in 2013 and had an urge to turn the divorce into a positive situation. Because he had been a music lover for many years and was also a professional teacher who had been educated as carpenter and had his own shop as a guitar builder, he wanted to make a tattoo to honor one of his idols, the famous Jimi Hendrix, who was a left-handed guitar player like JM himself. Not wanting a realistic photo but rather a graphic tattoo, we designed this piece of art, and he was very happy with it. 


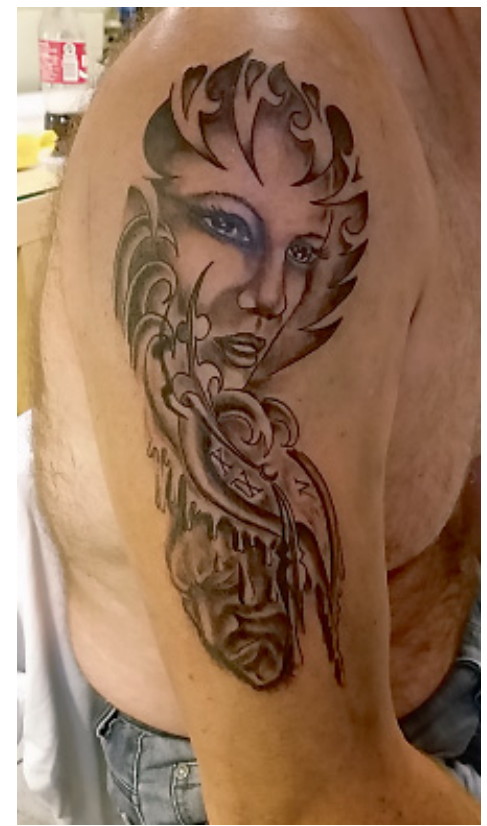

Fig. 2. Grief and eternal love. Tattoo and photo by author.

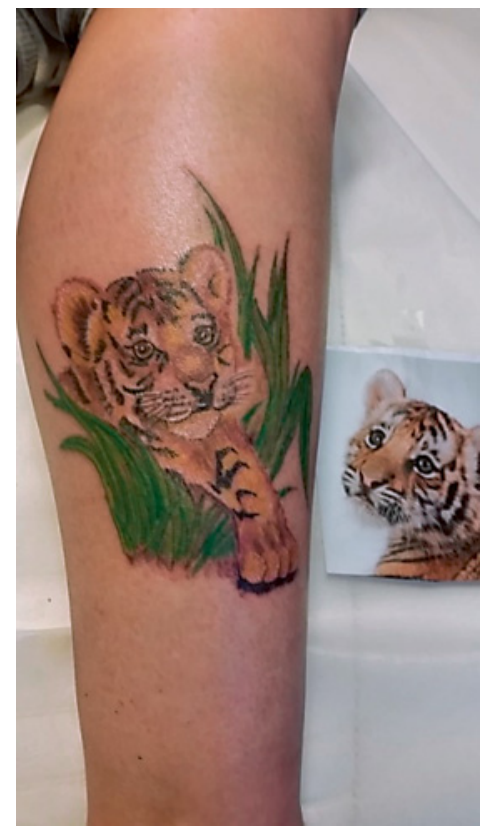

Fig. 3. Fragile soul. Tattoo and photo by author.

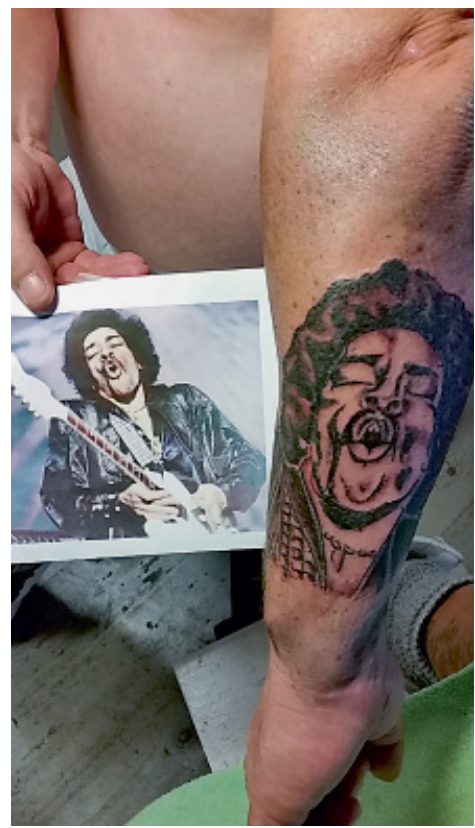

Fig. 4. Graphic style music legend. Tattoo and photo by author.

\section{Comments}

When I started getting tattoos in 1981, they were only for bikers, sailors, 'birds' in the streets (prostitutes) and guys down at the bar. When tribal art (black tattoos with intricate swirls and beautiful shapes) entered the tattoo scene in Denmark at the end of the 1980s and the beginning of the 1990s, other types of clients started to want tattoos. Tattoo designs don't necessarily need to have a specific look. This beautiful adornment of the body is drawn straight onto the skin with a pen following the anatomic shapes, resulting in a beautiful piece of art belonging only to the recipient. The very rigid and old-fashioned tattoo style of 'getting a tattoo from the wall' has changed, and individual artists' skills and talents are now challenged to create and draw according to their clients' recommendations.

It is very common that we are asked to help design artistic 'statements', or symbols with a cer- tain meaning rather than just actual lettering, for example, the 'living in the moment desire' to tattoo a unique design to mark a special occasion, whether it is sad or joyful. The real tattoo artist does not necessarily want to hear the story, but most people are anxious to tell the reason for their tattoo and their decision to become tattooed.

People have many reasons for wanting a tattoo. Currently, tattoos are everywhere, including in ads, in the news, and on actors, musicians, soccer players, disc jockeys and artists. Because it is possible to be exposed to many more tattoos compared with just a decade ago, people have become fascinated by the beautiful artwork that we are able to do, and tattoos have become more and more realistic, colorful, larger and more personal.

The decision to become tattooed greatly differs depending on the situation. There are the young and impatient clients who just want to become decorated right there and then. Their parents may come to professional studios begging for 
tattoos for their minors because they know that the young kids will go to any extent to get tattooed, even using at-home scratchers.

Others might have wanted a tattoo for many years. For middle-aged individuals, a life-changing situation may have occurred, such as having grandchildren, a divorce, death or separation. In the 1980s, it was very common for young men to celebrate the completion of military training by getting a tattoo.

During my time as a tattoo artist in Spain, where I tattooed mostly navy personnel from the 6th US fleet, tattooing symbolized being away, longing for home and at times, the loss of friends in combat.

Tattoo artists are very lucky because our clients are very loyal. In the earlier days before the internet, word of mouth was very important to tattoo artists. The recommendation of one particular artist by one satisfied client to another individual led to more clients wanting to get tattooed by that artist. At that time (1989), I felt that a lot of people thought that if the tattooist (the tattoo artist) was female, she would be gentler, and the tattoo hurt less. However, this is not true. The professional tattooist knows how to let the machine do the 'dancing' on the skin.
It has always struck me how deeply involved clients are with every little detail of their design. This is what makes the job so interesting and challenging, to capture a client's desire and wishes and bring the first drawing to life and then to do the actual tattoo. Once the design is finished and approved, the most important part of the process awaits, the actual tattooing session. It is kind of a build up to complete satisfaction, seeing the tattoo on the skin for the first time.

While tattooing, it seems that the intimacy between the tattoo artist and client creates a comfort zone, and clients usually feel free to tell their story. The acts of touching the skin and tattooing create an invisible bond, and it becomes a mutual task to make a beautiful piece of art.

Clients are always offered a second visit for a check-up, and they often bring family or friends along. Once at the tattoo studio, non-tattooed people get inspiration from looking at all of the books and magazines, photos and tattoo paraphernalia that always decorate an 'old school tattoo studio'. Currently, a new type of tattoo studio has been introduced to the tattoo scene. Chains of shops with very little or no decor and charm but often with very skilled artists represent the new trend in our trade.

Liz Kierstein

Independent Tattoo Artists

27, Fiolstraede

DK-1171 Copenhagen K (Denmark)

E-Mail tattoliz@gmail.com 